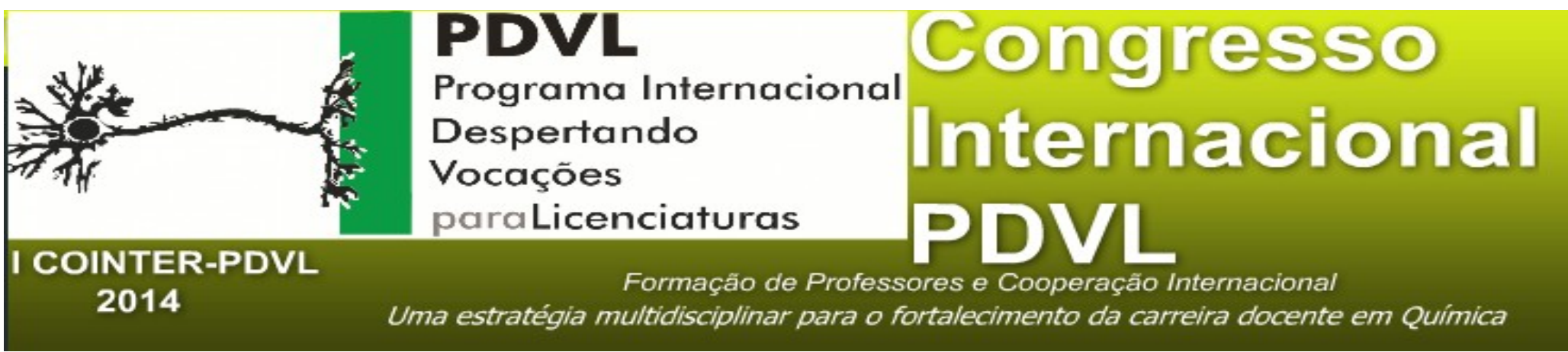

\title{
ABORDAGEM QUÍMICA DIALOGADA PARA JOVENS E ADULTOS UTILIZANDO EXPERIMENTOS ENDOTÉRMICOS E EXOTÉRMICOS
}

\author{
Apresentação: Comunicação Oral
}

\begin{abstract}
Flávia Rhuana Pereira Sales ${ }^{1}$; Niely Silva de Souza²; Mayzza Márcia Araújo do Nascimento; Alessandra Marcone Tavares Alves de Figueirêdo ${ }^{4}$
\end{abstract}

\section{Resumo}

Este trabalho foi estruturado numa metodologia dialogada dentro de uma perspectiva contextualizada visando uma aprendizagem em Química de forma mais dinâmica. Tal proposta didática foi realizada por um grupo de pesquisa do CNPq, do Instituto Federal de Educação, Ciência e Tecnologia da Paraíba com o tema Reações Endotérmicas e Exotérmicas junto a uma classe de jovens e adultos do terceiro ano do nível médio da Escola Estadual Maria de Lourdes Araújo, localizada em Santa Rita - PB. A unidade didática foi previamente esquematizada pelos componentes do grupo junto ao professor da turma participante partindo de uma expectação contextualizada que relaciona o conteúdo a vivência dos estudantes numa tentativa de incentivar/melhorar o processo de ensino-aprendizagem, tendo em vista que as pessoas que optam por cursar o EJA, em sua grande maioria são jovens, adultos e trabalhadores, que não dispõem de tempo hábil para estudo e possuem uma carga de conhecimentos próprios adquiridos em sua prática cotidiana. Por esse motivo, a aplicação foi realizada com o intuito de aproveitar tais conhecimentos e usá-los como uma ferramenta a fim de despertar o interesse do alunado no processo de ensinoaprendizagem, correlacionando a química com os conhecimentos empíricos dos estudantes. Para

\footnotetext{
Licenciatura em Química/IFPB Campus João Pessoa/CNPq/flavia.rhuana@outlook.com

2 Licenciatura em Química/IFPB Campus João Pessoa / CNPq/nila_mepb@yahoo.com.br

3 Licenciatura em Química/IFPB Campus João Pessoa / CNPq/mayzzaaraujo.quim @hotmail.com

4 Doutora/IFPB Campus João Pessoa/CNPq/alessatavares@yahoo.com.br
} 
tanto, utilizou-se experimentos sucintos envolvendo os alunos nas atividades, realizando reflexões sobre o mundo ao seu redor, estimulando deste modo à interação professor-aluno em aula e facilitando a compreensão desta temática. Com isso, pôde-se observar que a utilização de uma metodologia diferenciada estimulou os alunos a participarem ativamente das aulas, comprovando que a contextualização por meio da problematização do cotidiano juntamente com a experimentação, geram um diálogo motivacional e eficiente.

Palavras-Chave: Contextualização, Experimentação, Ensino de Química.

\section{Introdução}

O ensino de Ciências na grande parte das escolas públicas brasileiras ainda está moldado na adoção de metodologias defasadas. A prática curricular continua sendo predominantemente disciplinar, com uma visão fragmentada e linear dos conhecimentos na estrutura das próprias disciplinas. O ensino ainda é marcado pelo “conteudismo”, típico de uma relação de ensino tipo “transmissão - recepção”, em que o aluno não tem uma participação ativa em sala de aula.

$\mathrm{Na}$ maioria das escolas, as aulas de química são desenvolvidas de forma meramente tradicional, presas as memorizações e sem relação com a vida prática do aluno. Essa maneira simplista ultrapassada e até mesmo autoritária de conceber o processo de ensino, certamente não deixa transparecer a complexidade que caracteriza todo o ato de ensinar (NANNI, 2004). Desta forma, práticas pedagógicas que visem melhorar esse quadro são imprescindíveis, haja vista que esses professores fazem uso do método tradicional de aula, que no cenário atual, é apontado como um erro metodológico se aplicado demasiadamente, pois estudante é visto apenas como um mero recipiente que recebe e armazena as informações que lhes são passadas, retendo-as na memória e depois prestando contas, através de provas, testes e uma infindável série de exercícios repetitivos (FREIRE, 2002).

Quando falamos de alunos da Educação de Jovens e Adultos - EJA, a relevância da contextualização torna-se mais importante, uma vez que o público apresenta diferenças na aquisição do conhecimento, principalmente por estar inserido no mundo do trabalho e das relações entre as pessoas, de modo diferente da criança e do adolescente. Deste modo, a disciplina de Química deve ser passada de maneira que os jovens e adultos possam encontrar algum sentido e utilização sobre os conceitos e fórmulas químicas na sociedade, além da razão e o objetivo de aprender certo conteúdo em sala de aula estabelecendo uma aprendizagem significativa (BUDEL, 2008).

\section{Fundamentação Teórica}


A Educação de jovens e adultos (EJA) é uma modalidade de ensino de cunho inclusivo, pois visa à inserção de um público que está fora da faixa etária escolar adequada, necessitando de tratamento metodológico diferenciado (INRELAND, MACHADO e PAIVA, 2004) que considera o perfil do alunado, proporciona apropriação e a contextualização das diretrizes curriculares nacionais (BRASIL, 2000). No tocante à disciplina de química, a visão dos estudantes é de difícil assimilação e entendimento, pois exige dos alunos capacidade de abstração, interpretação e leitura. Essa situação torna-se mais agravante quando a disciplina é transmitida de maneira fragmentada, provocando uma dificuldade na compreensão do conteúdo pelo aluno que em grande parte não sabe o motivo e a importância de estar estudando um determinado conteúdo (SANTOS \& MORTIMER, 1999).

Quando o aluno, mediado pelo professor, consegue compreender a importância e a aplicabilidade do conteúdo químico no seu cotidiano, resulta na aprendizagem dos alunos da EJA de uma forma mais significativa. Schnetzler (1996) enfatiza que o ensino de química tem como função o desenvolvimento da capacidade de tomada de decisão, o que implica na necessidade de vinculação do conteúdo trabalhado ao contexto social em que o aluno está inserido. Diante desta necessidade de contribuir com o processo de ensino-aprendizagem de maneira significativa e diferenciada, embasada na contextualização, várias são as estratégias que podem ser utilizadas pelo professor.

Dentro desse âmbito supracitado “a experimentação pode ser uma estratégia eficiente para a criação de problemas reais que permitam a contextualização e o estímulo de questionamentos de investigação” (GUIMARÃES, 2009, p. 198) uma vez que relaciona a teoria com a prática, proporcionando a observação, ao raciocínio e a curiosidade dos estudantes. Dentro desse contexto, há necessidade de superar o atual ensino praticado, proporcionando o acesso a conhecimentos químicos que permitam a construção de uma visão de mundo mais articulada e menos fragmentada, contribuindo para que o indivíduo se reconheça como participante de relações direta com a ciência e suas tecnologias (BRASIL, 2006).

Diante do exposto, a disciplina de Química deve ser passada de maneira que os jovens e adultos possam encontrar algum sentido e utilização sobre os conceitos e fórmulas químicas na sociedade, além da razão e o objetivo de aprender certo conteúdo em sala de aula estabelecendo uma aprendizagem significativa (BUDEL, 2008).

\section{Metodologia}


A metodologia utilizada neste estudo será a pesquisa participante, segundo Severino (2008, p. 120) é definida como 'aquela em que o pesquisador, para realizar a observação dos fenômenos, compartilha a vivência dos sujeitos pesquisados, participando, de forma sistemática e permanente, ao longo do tempo da pesquisa, das suas atividades'.

O desenvolvimento deste estudo ocorreu na escola Estadual Maria de Lourdes, localizada na cidade de Santa Rita - PB, com a turma do terceiro ano do nível médio de jovens e adultos no turno da noite. A classe possui 40 (quarenta) alunos, dos quais 37 participaram de todos os momentos deste ensaio.

O professor de química da escola, que também é integrante do grupo de pesquisa que desenvolveu este trabalho, vem atuando com este alunado acerca de um ano. Durante esse período de convivência, observou atentamente as necessidades desse público, corroborando com um planejamento de aula mais eficiente, focado nos misteres dos discentes para conseguirmos uma participação discente mais ativa.

Desta forma, a metodologia planejada e aplicada buscou criar um ambiente escolar que proporcionasse a todo o alunado uma oportunidade de associar o conhecimento científico com o conhecimento popular, contribuindo assim, para um melhor processo de ensino e aprendizagem, tentando atribuir mais significado aos conceitos acadêmicos, bem como facilitando o trabalho docente em sala de aula.

Todas as etapas foram planejadas previamente com a participação e contribuição de todos os integrantes do grupo, para garantir que houvesse uma garantia das sequências didáticas entre os assuntos que seriam ministrados, e que os mesmos estivessem em consonância com a modalidade de ensino a qual se destinava. Conforme Leach et al (2005), as atividades que são planejadas de maneiras sequenciais podem contribuir para a aprendizagem de diversos conteúdos em ciências. A realização deste trabalho foi dividida em duas etapas.

$1^{\mathrm{a}}$ - Correspondente ao planejamento das atividades: Tal ação contou com a participação de todos os integrantes do grupo de pesquisa, incluindo o professor da turma, para sistematizar as ações da forma mais simples possível, mas sem perder as características didático-pedagógicas do conteúdo químico; discutiu-se e foram selecionadas as práticas a serem realizadas na sala, bem como o roteiro delas.

$2^{\mathrm{a}}$ - Correspondente à aplicação da atividade em sala de aula: Para a sua realização foram necessárias duas aulas de 35 (trinta e cinco) minutos cada. Nesta etapa foram realizados três experimentos, com o intuído de demonstrar e facilitar o entendimento dos discentes perante o desenvolvimento do conteúdo. 


\section{Resultados e Discussões}

Para iniciar a aplicação, foram feitos alguns questionamentos aos alunos a respeito dos conteúdos que seriam trabalhados e àqueles não conseguiram responder. A equipe, percebendo esta dificuldade dos alunos, promoveu uma explanação breve dos temas que seriam abordados com o objetivo de identificar o conhecimento prévio que os discentes tinham.

Depois, o professor perguntou aos alunos se eles conseguiriam identificar alguma reação química exotérmica ou endotérmica no seu cotidiano. Vários alunos tentaram responder, porém nenhum chegou a uma resposta que representasse alguma das reações. Devido a essa problemática, o professor decidiu oferecer subsídios para que os alunos refletissem e conseguissem identificar ao menos um tipo de reação ao perguntar aos seus alunos se eles tinham tomado café da manhã. A grande maioria respondeu que sim e uma minoria salientou que não, pois havia se atrasado para ir ao trabalho.

Então, o professor indagou "o que vocês comeram hoje pela manhã? alguém utilizou o fogão?”. Os alunos mencionaram o que haviam comido e muitos deles informaram que não tinham utilizado o fogão, pois consumiram apenas algumas frutas; em determinado momento um aluno chamou a atenção do professor, com o seguinte diálogo “professor, professor, já sei! É o gás né?”, em seguida o professor respondeu “exato aluno, parabéns pela observação”.

Assim sendo, o professor explanou aos educandos que para preparar café, por exemplo, é preciso aquecer a água. Esse processo que vai liberar certa quantidade de energia e assim possibilitar o aquecimento da água, que ocorre a partir da combustão do gás de cozinha (reação exotérmica), demonstrada pela reação de combustão de um dos componentes do gás de cozinha, o gás butano.

$$
\mathrm{C}_{4} \mathrm{H}_{10(\mathrm{~g})}+13 / 2 \mathrm{O}_{2(\mathrm{~g})} \rightarrow 4 \mathrm{CO}_{2(\mathrm{~g})}+5 \mathrm{H}_{2} \mathrm{O}_{(\mathrm{g})}+\text { calor }
$$

Após a explicação acima, o professor perguntou aos alunos se eles tinham o costume de lavar roupas; muitos responderam que não, pois esse serviço ficava por conta das companheiras, mas uma porção da turma (mulheres) respondeu que sim. A este grupo indagou-se como elas faziam isso e as respostas foram unânimes: uso do sabão em pó. Então o professor arguiu se elas sentiam alguma diferença de temperatura quando adicionavam o sabão em pó sobre as roupas e mais uma vez a resposta foi unânime: todas sentiam a mão esquentar quando colocavam o sabão.

Quando o professor da turma questionou o porquê dessa sensação, nenhum aluno conseguiu chegar a uma conclusão, logo o docente explicou que esse fato ocorre por conta da presença de uma substância química no sabão em pó, chamada de hidróxido de sódio, que em contato com a água 
resulta numa reação de dissociação, liberando energia (exotérmica) que as estudantes sentiam através do tato.

Como a sensação descrita não era comum a todos os alunos, foi executado a primeira prática (Figura 1), a qual foi adicionada aproximadamente $5 \mathrm{~g}$ de hidróxido de sódio em $50 \mathrm{~mL}$ de água.

$$
\mathrm{NaOH}_{(\mathrm{s})} \stackrel{\mathrm{H} 2 \mathrm{O}}{\longrightarrow} \mathrm{Na}^{+}+\mathrm{OH}^{-}
$$

A dissociação do hidróxido de sódio no cátion $\mathrm{Na}^{+}$(íon sódio) e ânion $\mathrm{OH}^{-}$(íon hidroxila), em água, trata-se de um processo de natureza exotérmica. A energia liberada é tão perceptível que não é necessário de instrumentação para perceber tal energia, o recipiente no momento da adição do hidróxido esquentou consideravelmente que pôde ser determinada pelo aumento da temperatura.

A equipe do projeto convidou três alunos, propositalmente, pois esses tinham informado que nunca haviam lavado roupa e consequentemente não imaginavam como seria o exemplo de reação exotérmica discutido em sala de aula.

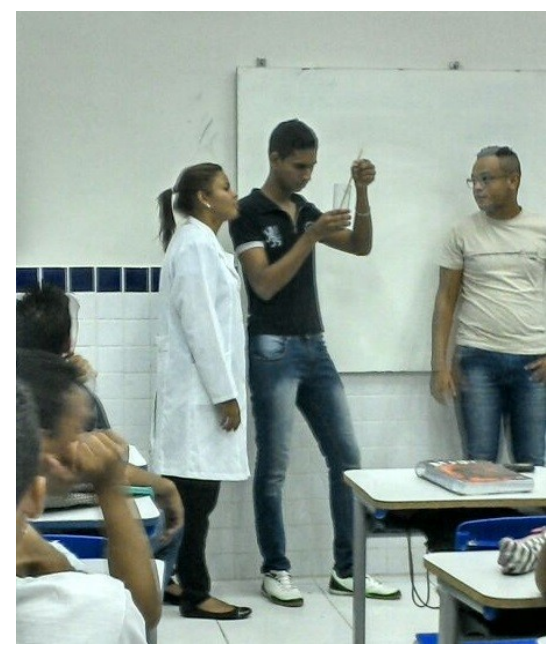

Figura 1- Aplicação da primeira prática: reação exotérmica. Fonte: Própria.

Após o experimento, perguntou-se aos alunos se eles tinham gostado da prática e todos responderam que sim. Uma das respostas dadas chamou a atenção do professor "eu nem imaginava que essas pedrinhas podiam aquecer a água, ficou quente mesmo, não da nem pra segurar o copo”. A energia liberada de dissociação foi comprovada pelo aumento da temperatura, que foi medido no termômetro pelo aluno com um resultado de $48^{\circ} \mathrm{C}$.

Frente ao experimento, os alunos ficaram curiosos para saber como seria uma reação endotérmica, então o professor os desafiou a identificar esse tipo de reação no cotidiano deles. E, novamente, muitas respostas foram dadas, mas nenhuma coerente. A equipe decidiu iniciar a segunda prática (Figura 2) convidando dois alunos para virem à frente da sala. Dois chumaços de algodão foram embevecidos no líquido contido num recipiente não identificado e passou os chumaços de algodão no braço de cada um dos alunos. 


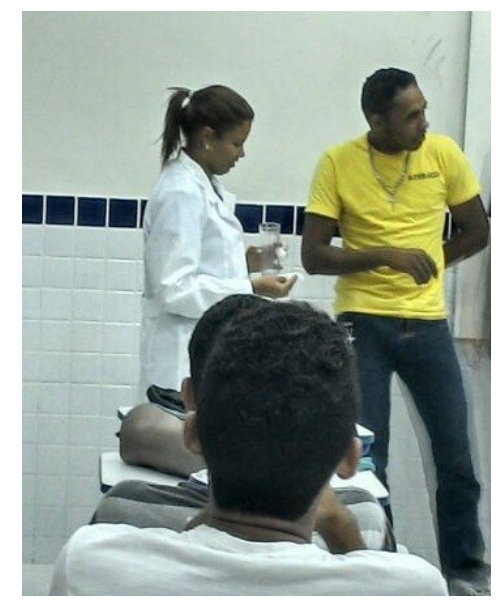

Figura 2 - Aplicação da segunda prática: reação endotérmica. Fonte: Própria.

Posterior ao contato dos alunos com os chumaços de algodão, perguntou-se qual a sensação que eles sentiram. Os dois falaram que o local ficou mais frio; então foi solicitado aos dois alunos que assoprassem a parte de pele molhada, logo após houve a indagação “qual a sensação?” e os dois alunos responderam que o local ficou mais gelado. O professor explicou que era o álcool comum (etílico), substância volátil que precisa de energia para evaporar, e tal energia é "tirada” da nossa pele na forma de calor; essa reação é considerada endotérmica, já que para ela ocorrer, precisa de calor. Esse fenômeno físico ocorre através da agitação das moléculas do álcool, que em contato com a pele absorve o calor (energia térmica) necessário para que passe do estado líquido para o estado de vapor, causando a sensação de frio na pele.

Em seguida, o professor perguntou aos alunos quais eram as formas de "produzir" fogo e várias respostas foram dadas. O professor lançou o seguinte desafio, “como é que a gente pode fazer fogo sem utilizar nenhuma dessas técnicas? Não vale fósforo, isqueiro, atrito, nenhuma delas, como a gente conseguiria produzir fogo? Será que existe alguma forma?”. A turma debateu e afirmou que seria impossível, não havia como fazer fogo sem nenhuma dessas ações. Diante dessa conclusão dos alunos, o professor iniciou o terceiro experimento (Figura 3) com dois compostos e demonstrou ao grupo de estudantes como a química é fascinante. Foi utilizado a glicerina em solução e o permanganato de potássio em comprimido, ambos adquiridos em farmácia. Inicialmente foi aumentado a superfície de contato dos comprimidos, triturando-os, em seguida colocados em cima de uma folha de papel e foi adicionado três gotas de glicerina sobre o pó. 


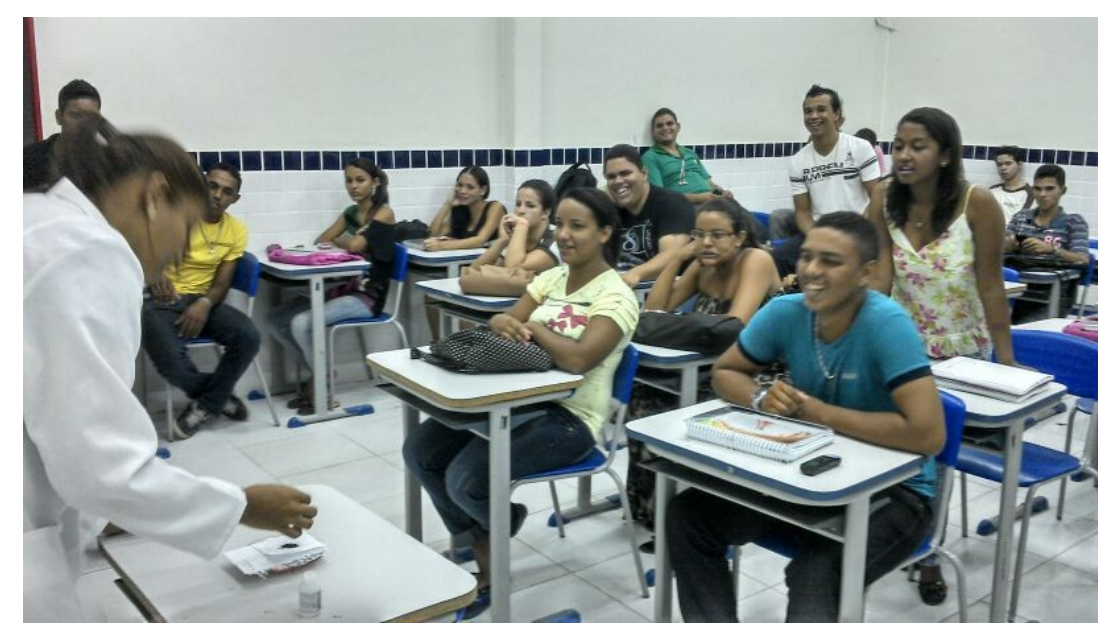

Figura 3 - Terceiro experimento: reação exotérmica. Fonte: Própria.

Os referidos compostos quando em contato, iniciam um processo de combustão espontânea.

$$
14 \mathrm{KMnO}_{4(\mathrm{~s})}+4 \mathrm{C}_{3} \mathrm{H}_{5}(\mathrm{OH})_{3(\mathrm{aq})} \rightarrow 7 \mathrm{~K}_{2} \mathrm{CO}_{3(\mathrm{~s})}+7 \mathrm{Mn}_{2} \mathrm{O}_{3(\mathrm{~s})}+5 \mathrm{CO}_{2(\mathrm{~g})}+16 \mathrm{H}_{2} \mathrm{O}_{(\mathrm{g})}
$$

O permanganato de potássio por ser um agente oxidante muito forte provoca a oxidação da glicerina liberando uma energia muito alta que é perceptível pela presença da chama. A reação é extremamente exotérmica, liberando uma grande quantidade de energia em forma de calor capaz de iniciar o processo de combustão do papel, gerando uma chama por todo material inflamável (Figura 4).

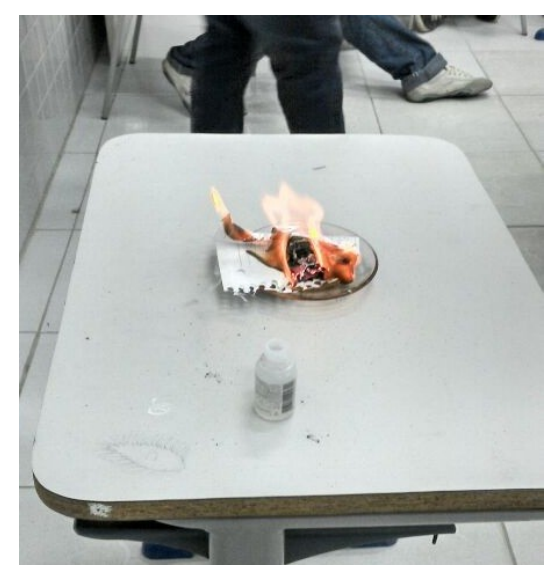

Figura 4 - Demonstração do terceiro experimento. Fonte: Própria.

Ao final deste experimento foi perceptível à empolgação dos alunos, eles ficaram fascinados com a reação exotérmica e perguntaram quais os compostos eram necessários para o experimento, mas por questões de segurança preferiu-se não divulgar os componentes da reação, e sim ratificar os conceitos químicos envolvidos na vivência didática.

Durante o desenvolvimento da prática foi notório o interesse da turma, pois o que até então era abstrato agora possuía um significado. Durante o procedimento surgiram discussões, 
contextualizando com fatos do cotidiano. A realização desta atividade experimental deve estar relacionada a uma estratégia eficiente para a criação de problemas reais que permitam a contextualização e estimule questionamentos (GUIMARÃES, 2009).

Para finalizar a aplicação à equipe realizou uma breve revisão dos conteúdos trabalhados para averiguar o grau de significância que eles tiveram para os alunos envolvidos na aplicação a partir de um questionamento final, então o professor interpelou os estudantes sobre os tipos de reações vistos na aula e um aluno afirmou com consentimento da turma "reação endotérmica absorve energia e a exotérmica libera né professor!”, tendo assim um resultado satisfatório, pois quase todos ali presentes demonstraram com suas opiniões que as aplicações foram válidas o que os conceitos ali trabalhados foram aprendidos.

\section{Conclusões}

O uso de uma metodologia diferenciada estimulou os alunos, fazendo com que eles prestassem atenção, tirassem dúvidas e buscassem um aprendizado mais significativo. A abordagem do conteúdo relacionado ao cotidiano dos alunos trouxe um desenvolvimento intuitivo e cognitivo, comprovando que a aula dialogada através da problematização e das experiências de vida juntamente a experimentação facilita a observação e a compreensão dos tópicos químicos abordados.

Diante do exposto pode-se identificar que o professor deve planejar e buscar ferramentas didáticas diferenciadas para obter a compreensão dos alunos a partir do saber popular e do mundo do trabalho, fazendo com que os estudantes não sejam passivos, mas sim cidadãos pensantes, críticos e produtores do seu próprio conhecimento.

\section{Referências}

BRASIL: Resolução no ${ }^{\mathbf{1}}$, de $\mathbf{5}$ de julho de 2000. Estabelece as Diretrizes Curriculares Nacionais para a Educação de Jovens e Adultos. Brasília: Conselho Nacional de Educação-Câmara de Educação Básica. Disponível em: http://www.eja.org.br/dernometodologico/resolucoes/index.php? acao3_cod0=09ec1cb8bacebfebbbe0dfcdb90c96c4> Acesso em 12 de setembro de 2014. 
BUDEL, G. J. Ensino de Química na EJA: Uma proposta metodológica com abordagem do cotidiano. Universidade Federal do Paraná, pp.1-21, 2008.

FREIRE, P. Pedagogia do Oprimido. Rio de Janeiro: Paz e Terra, Freire, 2002.

GUIMARÃES, C. C. Experimentação no ensino de química: caminhos e descaminhos rumo à aprendizagem significativa. Química Nova na Escola, v. 31, no 3, p. 198 - 202, 2009.

IRELAND, T.; MACHADO, M. M.; PAIVA, J. (orgs). Declaração de Hamburgo sobre educação de adultos - V CONFINTEA. In: Educação de Jovens e Adultos. Uma memória contemporânea 1996 - 2004. Brasília: MEC: UNESCO, 2004. (Coleção Educação para Todos) p. 41-49.

LEACH, J.; AMETLLER, J.; HIND, A.; LEWIS, J., \& SCOTT, P. Designing and evaluating short science teaching sequences: improving student learning. Research and Quality of Science Education. Holanda: Springer. 209-220. (2005).

NANNI, R. Natureza do conhecimento científico e a experimentação no ensino de ciências. Revista eletrônica de ciências. São Carlos - SP, n. 24, 26 de maio de 2004. Disponível em: <http://cdcc.sc.usp.br/ciencia/artigos/art_26/natureza.html>. Acesso em: 22/09/2014

SANTOS, F.M.T.D.; MORTIMER, E.F. Estratégias e Táticas de Resistência nos primeiros dias de aula de química. Química Nova na Escola, n.10, pp. 38-42, 1999.

SCHNETZLER, R. P.; SANTOS, W. L. P. Função Social. O que significa o ensino de química para formar o cidadão? Química Nova na Escola, n.4, p.1-7, nov. 1996.

SEVERINO, A. J. Metodologia do trabalho científico. 23ª edição. São Paulo: Cortez, 2008. 